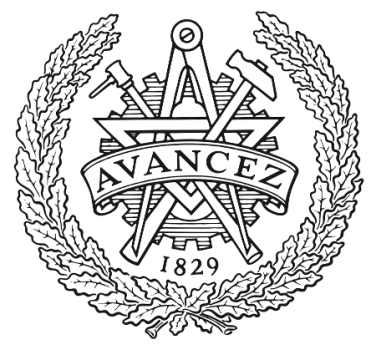

CHALMERS

UNIVERSITY OF TECHNOLOGY

\title{
CM \& Line-Dm Noise Separation for Three-Level NPC Inverter with Connected Neutral Point for Vehicle Traction Applications
}

Downloaded from: https://research.chalmers.se, 2023-04-26 12:31 UTC

Citation for the original published paper (version of record):

Kersten, A., Oberdieck, K., Gossmann, J. et al (2019). CM \& Line-Dm Noise Separation for Three-Level NPC Inverter with Connected Neutral Point for Vehicle Traction Applications. ITEC 2019 - 2019 IEEE Transportation Electrification Conference and Expo, June 2019: 1-6. http://dx.doi.org/10.1109/ITEC.2019.8790588

N.B. When citing this work, cite the original published paper. 


\title{
CM \& Line-DM Noise Separation for Three-Level NPC Inverter with Connected Neutral Point for Vehicle Traction Applications
}

\author{
Anton Kersten ${ }^{1}$, Karl Oberdieck ${ }^{2}$, Jerome Gossmann ${ }^{2}$, Andreas Bubert ${ }^{2}$, \\ Rolf Loewenherz ${ }^{2}$, Markus Neubert ${ }^{2}$, Emma Grunditz ${ }^{1}$, Torbjörn Thiringer ${ }^{1}$, and Rik W. De Doncker ${ }^{2}$ \\ ${ }^{1}$ Chalmers University of Technology, Gothenburg, Sweden \\ Email: kersten@chalmers.se \\ ${ }^{2}$ Institute for Power Electronics and Electrical Drives (ISEA), RWTH Aachen, Germany \\ Email: post@isea.rwth-aachen.de
}

\begin{abstract}
EMI standards limit the noise level for conducted disturbances on DC power cables of electric vehicles. However, designing the EMI filter requires the information about the $\mathrm{CM}$ and DM noise levels. Therefore, a separation of the noise is needed. This paper deals with the separation and quantification of the three-phase DM and CM noise for a three-level NPC inverter with a connected neutral point. A hardware separator, based on $\mathrm{HF}$ transformers was developed to separate the noise into $\mathrm{CM}$ and line-DM noise. The CM and line-DM noise of the NPC inverter was measured, when operating the inverter with a two-level and a three-level modulation. As expected, the CM noise is dominating, and it is shown that the three-level operation reduces the noise compared to the two-level operation by about 3 to $6 \mathrm{~dB}$.
\end{abstract}

\section{INTRODUCTION}

In modern electric vehicles, the proper functioning of all electronic devices must be ensured to guarantee a proper and safe operation of the entire vehicle. The traction inverter bears a high risk of electromagnetic interference with other onboard or surrounding devices. Therefore, standards, like the CISPR 25 [1], classify and limit the noise magnitude levels on power cables relative to the frequency within the range of $150 \mathrm{kHz}$ to $30 \mathrm{MHz}$. For the application of noise mitigation techniques, as for example the design of EMI filters, the knowledge about the DM and CM noise levels must be known. Converters with wide-bandgap semiconductors can achieve very high switching frequencies, while maintaining a high inverter efficiency, due to increased voltage and current slew rates. The drawback of this are increased conducted emissions [2]-[5]. This makes the design of the EMI filter for fast switching converters challenging, especially for high DC-link voltages, as for example $800 \mathrm{~V}$ [6].

Within the field of vehicle traction applications, the three-level Neutral Point Clamped (NPC) inverter is gaining interest due to its advantages like efficiency enhancement, fault tolerance and especially low output voltage harmonic and disturbance emissions [7]-[10]. In [8], [10], the three-level NPC inverter with connected neutral point is under consideration. In case of single type inverter switch faults, the vehicle's power train can be operated further, referred to as "limp home" mode.

Nevertheless, the available literature does not cover the separation and quantification of the conducted emissions of the three-level NPC inverter with its Neutral-Point connection (NP con.). Since the dual battery system forms a three-wire DC supply, the common two-wire CM and DM consideration, as described in [3], does not hold any longer. Therefore, this paper deals with the three-phase DM and CM separation and its quantification for a three-level NPC inverter with a connected neutral point. A hardware separator was developed and used to quantify the CM and DM conduction emissions on the DC-link rails.

\section{NPC INVERTER With NEUTRAL-POINT CONNECTION}

Commonly, the three-level NPC inverter is supplied by a single DC source, as can be seen in Fig. 1(a). Each capacitor

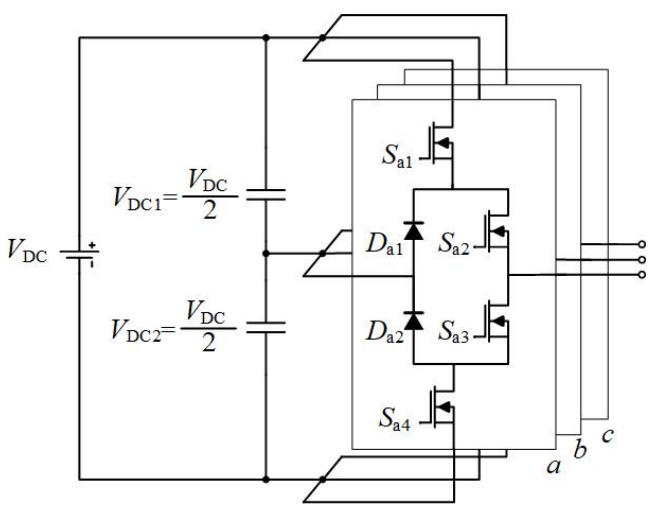

(a)

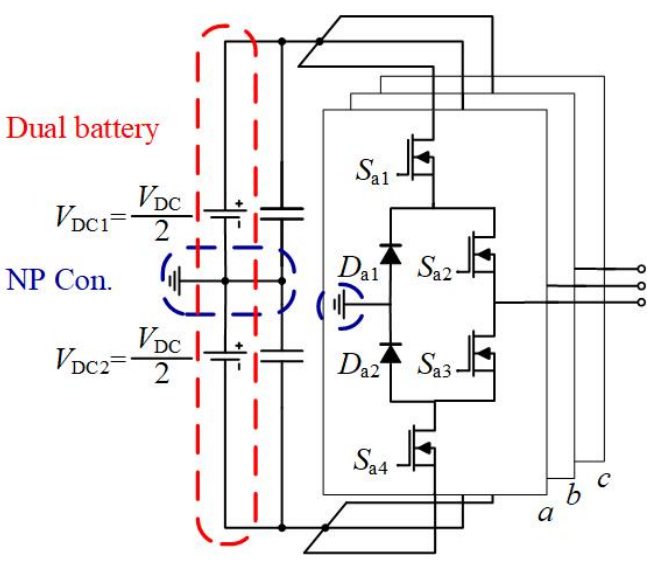

(b)

Fig. 1: Common three-level NPC inverter without (a) and with additional NP connection including split battery (b) [8]. 
has a nominal voltage equal to half of the DC-link voltage. However, a third-harmonic component is conducted on the positive and negative DC-link rail, closing through the capacitors and the neutral point of the inverter [11]. This, in turn, leads to an oscillation of the capacitor voltages, so that a switch can suffer a higher voltage than under nominal conditions. Several modulation techniques can be found in literature to mitigate these oscillations. However, the adaption of the modulation technique comes with the cost of increased switching losses [10], [12]. Furthermore, in case of an inverter fault, as an open or short circuit switch fault, the controllability of the drivetrain is lost [8]. A neutral-point connection to a dual battery system, as shown in Fig. 1(b), ties the capacitor voltages to the battery potentials. Thus, another low impedance path through the battery packs is provided for the third harmonic component. Thereby, the voltage swing of the neutral point is eliminated and in case of a single inverter switch fault, as described in [8], the drive train can still be operated with limited power.

\section{LINE-DM \& CM NOISE SEPARATION}

Since the three-level NPC inverter is supplied by a dual battery with a connected neutral point, the DC side cannot be considered as a classical two-wire inverter system. Thus, it must be dealt with a three-wire or three-phase CM/DM system, as depicted in Fig. 2. The definition and separation of three-phase DM/CM quantities is already known from classical three-phase AC systems, as for example described in [13]. For the noise measurement, three Line Impedance Stabilization Networks (LISN), often referred to as Artificial Mains Networks (AMN), are used to have a defined impedance. These are required to couple the high frequency noise into the measurement equipment, whereas the low frequency components are still conducted via the DC-link rails. When measuring the noise levels, each output of the LISNs must be terminated by $50 \Omega$, either by the spectrum analyzer's input or by external terminations, to provide a symmetric measurement condition.

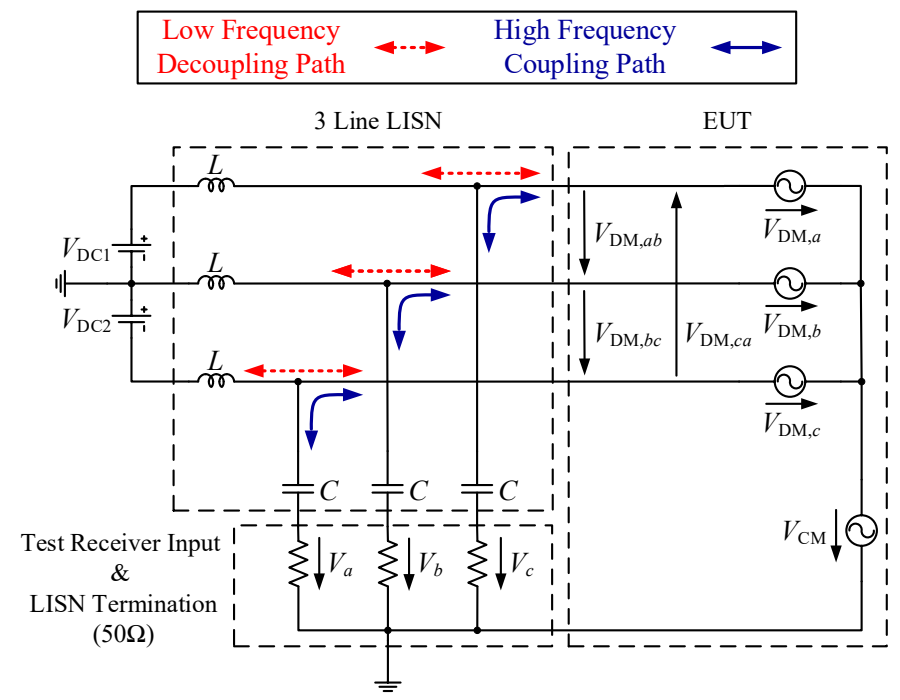

Fig. 2: Schematic of the noise measurement, including three LISNs.

As seen from the measurement scheme, the CM noise of the three-wire system is defined as the mean of the three LISN measurement outputs as

$$
V_{\mathrm{CM}}=\frac{V_{a}+V_{b}+V_{c}}{3},
$$

whereas each of the three phase-DM noise spectra can be determined by the corresponding line-measurement output and the $\mathrm{CM}$ noise as

$$
V_{\mathrm{DM}, x}=V_{x}-V_{\mathrm{CM}} \quad \text { with } \quad x=\{a, b, c\} .
$$

Consequently, the line-DM noise spectra can be obtained by the subtraction of two measurement outputs as

$$
V_{\mathrm{DM}, x y}=V_{x}-V_{y} \quad \text { with } \quad x y=\{a b, b c, c a\} .
$$

Equations (1) to (3) are referred to as noise separation. However, it should be noted that the noise separation is quite challenging, since the phase angle of the noise components must be taken into account. Therefore, a single channel spectrum analyzer cannot distinguish DM and CM quantities. In literature, several approaches of hardware separators, utilizing passive or active circuitry like operational amplifiers, can be found [3], [13]-[15]. For this article's investigation, a compact hardware separator based on HF transformers was developed for the NPC inverter, as shown in Fig. 3. This separator combines the CM and line-DM measurement topologies from [13], commonly used for AC supplied systems. For the PCB

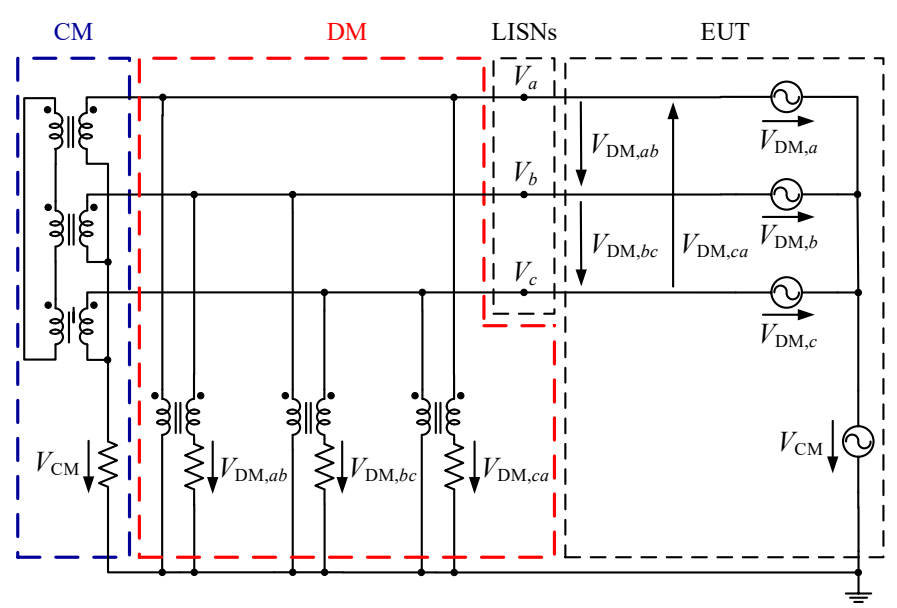

Fig. 3: Schematic of the three-phase noise separator.

realization, the TC1-42x+[16] small circuit HF-transformers from Minicircuits were used, as can be seen in Fig. 4. The

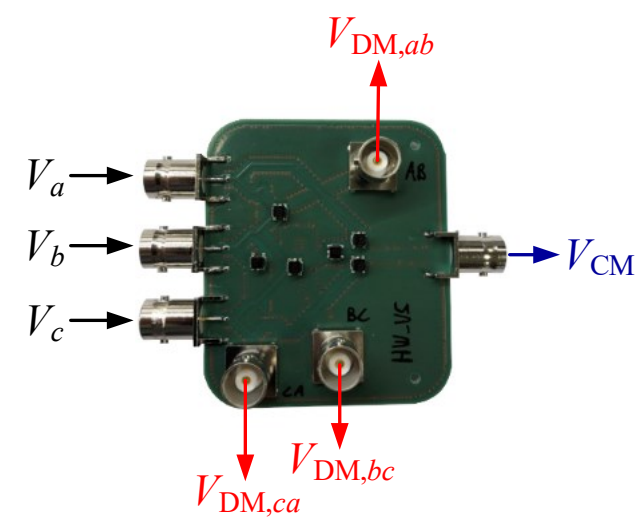

Fig. 4: PCB of the noise separator. 
chosen HF transformers have an operational frequency range from $250 \mathrm{kHz}$ to $400 \mathrm{MHz}$ with a typical insertion loss of $0.3 \mathrm{~dB}$. The performance of the three-phase noise separator can be characterized by the following quantities:

1. CM Transmission Ratio $(C M T R)$ :

$$
C M T R(f)=\left|\frac{V_{\mathrm{CM}, \text { out }}}{V_{\mathrm{CM}, \text { in }}}\right|
$$

2. Line-DM Transmission Ratios $\left(D M T R_{x y}\right)$ :

$$
D M T R_{x y}(f)=\left|\frac{V_{\mathrm{DM}, x y, \text { out }}}{V_{\mathrm{DM}, x y, \text { in }}}\right| \quad \text { with } x y=\{a b, b c, c a\}
$$

3. CM Rejection Ratios $\left(C M R R_{x y}\right)$ :

$$
C M R R_{x y}(f)=\left|\frac{V_{\mathrm{DM}, x y, \text { out }}}{V_{\mathrm{CM}, \text { in }}}\right| \quad \text { with } x y=\{a b, b c, c a\}
$$

4. Line-DM Rejection Ratios $\left(D M R R_{x y}\right)$ :

$$
D M R R_{x y}(f)=\left|\frac{V_{\mathrm{CM}, \text { out }}}{V_{\mathrm{DM}, x y, \text { in }}}\right| \quad \text { with } x y=\{a b, b c, c a\}
$$

The measured CM and DM characteristics of the separator are shown in Figs. 5(a) and 5(b), respectively. The Common Mode

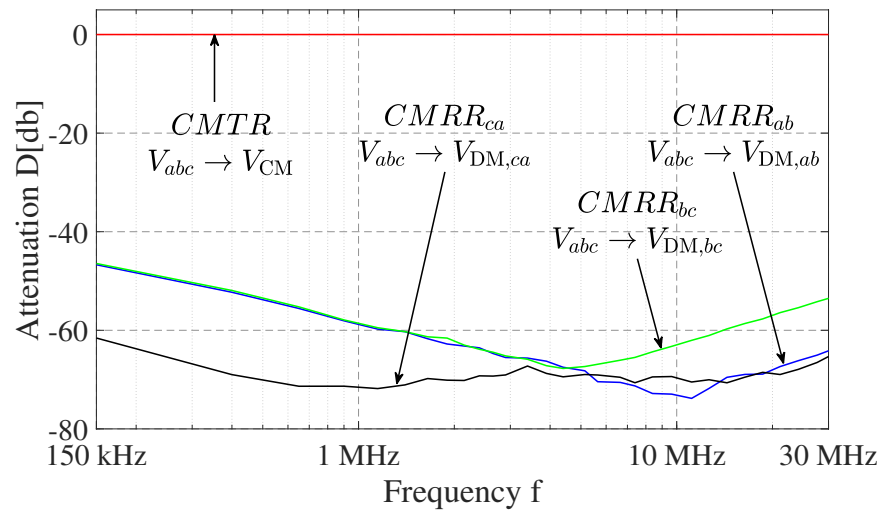

(a)

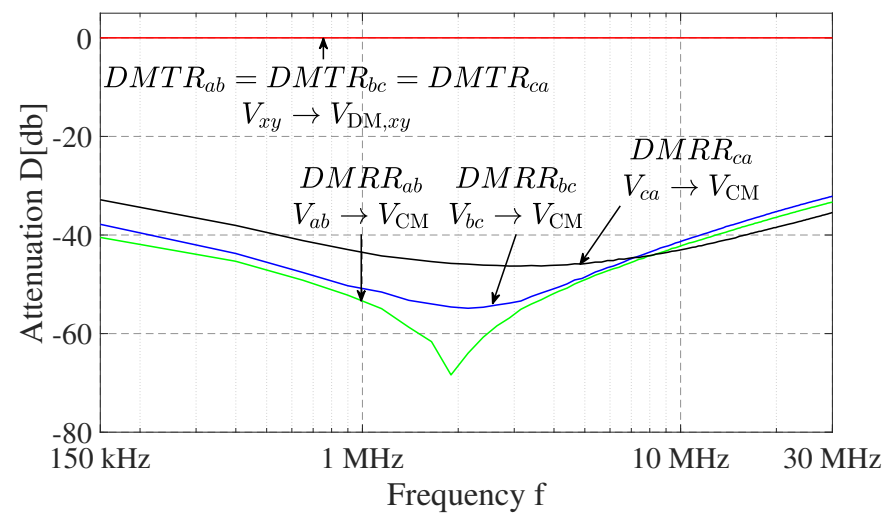

(b)

Fig. 5: Common mode (a) and differential mode (b) characteristic of the noise separator.

Transmission Ratio (CMTR) and the Differential Mode Transmission Ratios (DMRR) are about $0 \mathrm{~dB}$ for the considered frequency range, so that the CM and DM noises are unattenuated transmitted to the corresponding output. The CMRRs of the three DM outputs are at least $-46 \mathrm{~dB}$, which corresponds to an attenuation of $0.5 \%$ relative to the input signal. The DMRR characteristics show a minimum attenuation of $-32 \mathrm{~dB}$, which corresponds to an attenuation of $2.5 \%$ relative to the input signal.

\section{NPC INVERTER TESTBED}

The previously described hardware separator was used to quantify the DM and CM noise of an NPC inverter with a connected neutral point. The prototype of the IGBT based NPC inverter can be seen in Fig. 6. It utilizes the SKM300MLI066TAT three-level phase-leg modules of Semikron with a nominal blocking capability of $600 \mathrm{~V}$ and a current rating of $300 \mathrm{~A}$ [17]. A nominal DC-link voltage of $V_{\mathrm{DC}}=400 \mathrm{~V}$ was

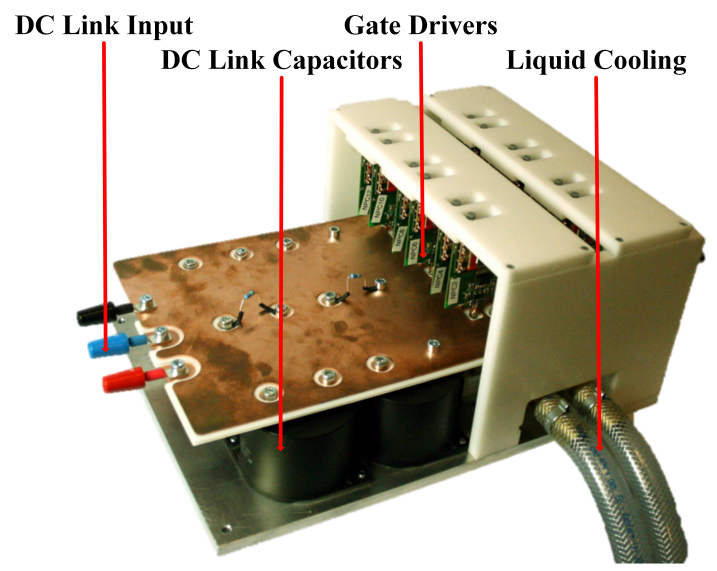

Fig. 6: NPC inverter prototype.

chosen, so that each DC-link capacitor was supplied by $200 \mathrm{~V}$. The inverter was operated with a switching frequency of $f_{s w}=10 \mathrm{kHz}$. It should be noted that the switching frequency of a multilevel inverter is referred to as the average frequency at which a phase leg is operated and should not be misinterpreted as the pulse frequency, referring to the frequency at which step-wise variations of the output voltage occur [18]. A custom-made three-phase RL load, utilizing an aircoil, was used as an artificial machine load, as shown in Fig. 7.

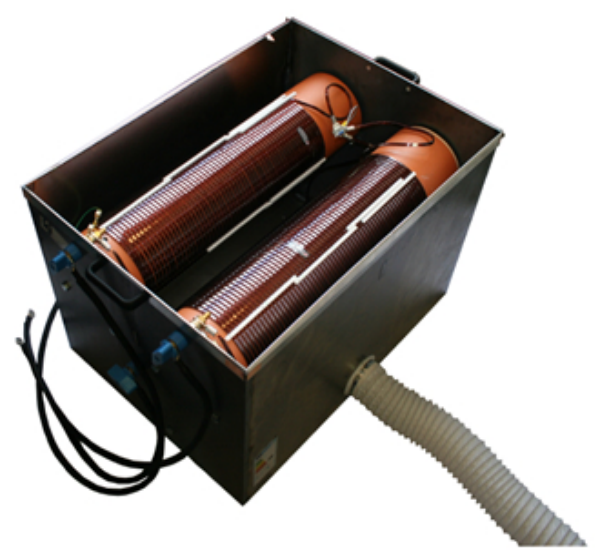

Fig. 7: Three-phase RL load, aircoil with forced air cooling. 
Each phase had a nominal inductance of $220 \mu \mathrm{H}$ and a resistance of $50 \mathrm{~m} \Omega$. The current rating was about $125 \mathrm{~A}_{\mathrm{RMS}}$, using forced air cooling. The laboratory test-bench can be seen in Fig. 8. The surface of the test bench was covered by a grounded copper sheet. Spacers were used to have a defined distance between the test equipment and the grounding plate. The outputs of the three LISNs were connected to the noise-separator and the measured noise signal was fed from the testbed to the spectrum analyzer. During the investigation,

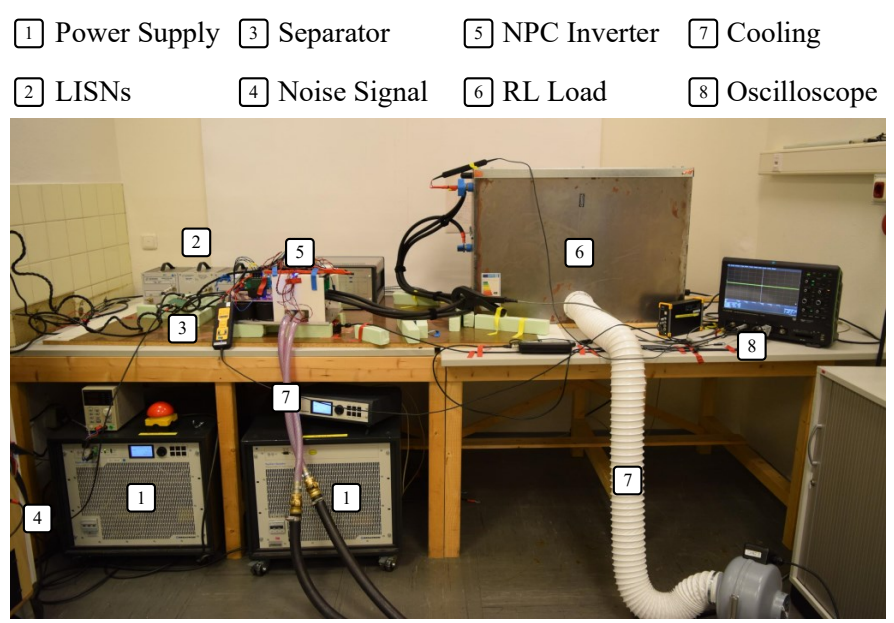

Fig. 8: EMI measurement testbench for three-level NPC inverter.

the inverter was operated either with three-level space-vector modulation, as described in [19], or by classical two-level modulation (avoidance of small vectors [8]). An open-loop control approach, using a fixed modulation index, was chosen. The blanking time and the voltage drop across the semiconductor switches were not taken into account. Fig. 9 shows the load current in phase $a$, when using three-level and two-level operation. The fundamental frequency was set to $500 \mathrm{~Hz}$ and

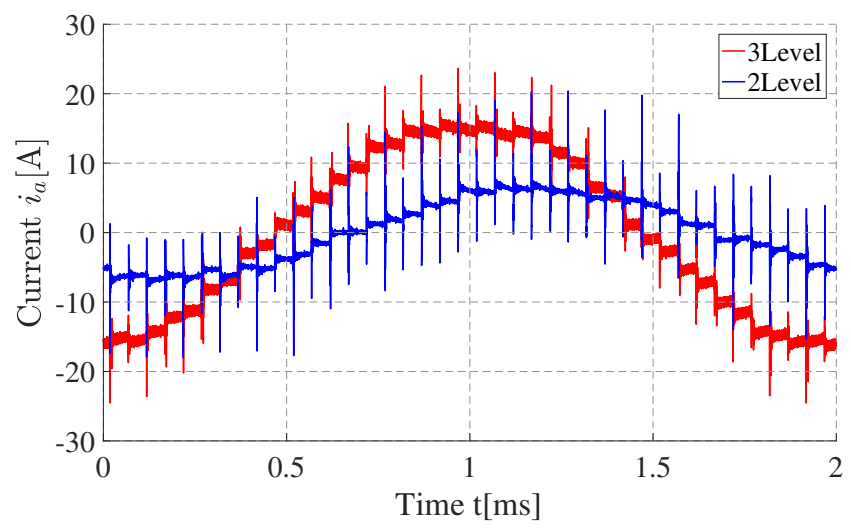

Fig. 9: Single-phase load currents for three-level and two-level operation.

the modulation indices were chosen to be $7.5 \%$ and $3.75 \%$ for the two-level and three-level modulation, respectively. From the measurements, it was seen that the variation of the modulation index does not affect the measured spectrum. It should be noted, the maximum possible modulation index was about $23 \%$ due to the given current rating.

\section{NOISE SPECTRUM OF THE NPC INVERTER}

Figure 10 shows the obtained spectra at the outputs of the three LISNs. Two typical resonance peaks were observed.

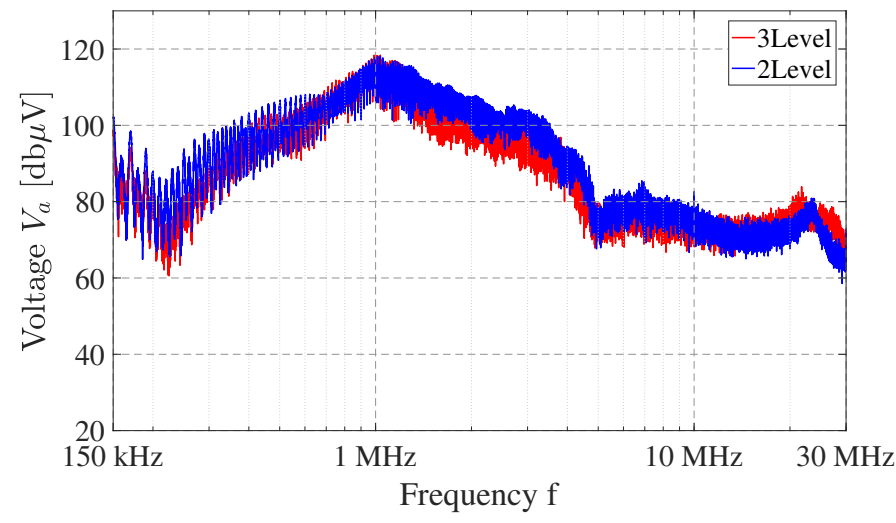

(a)

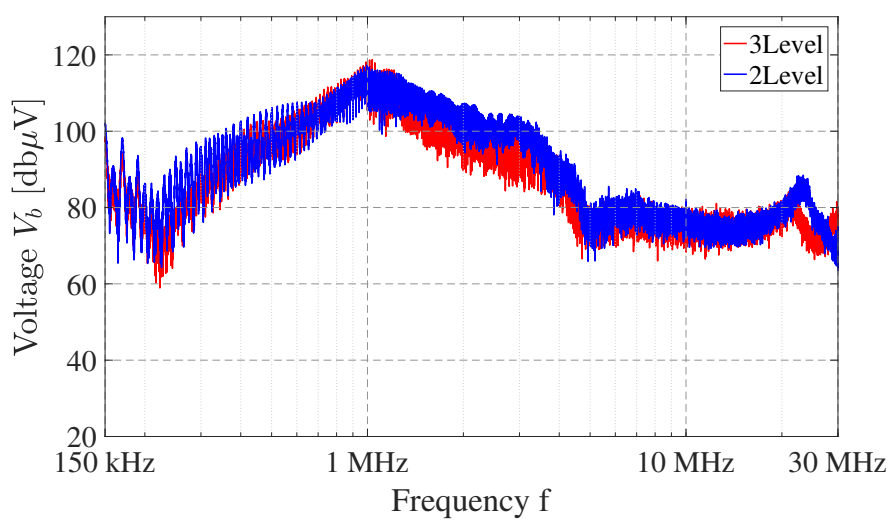

(b)

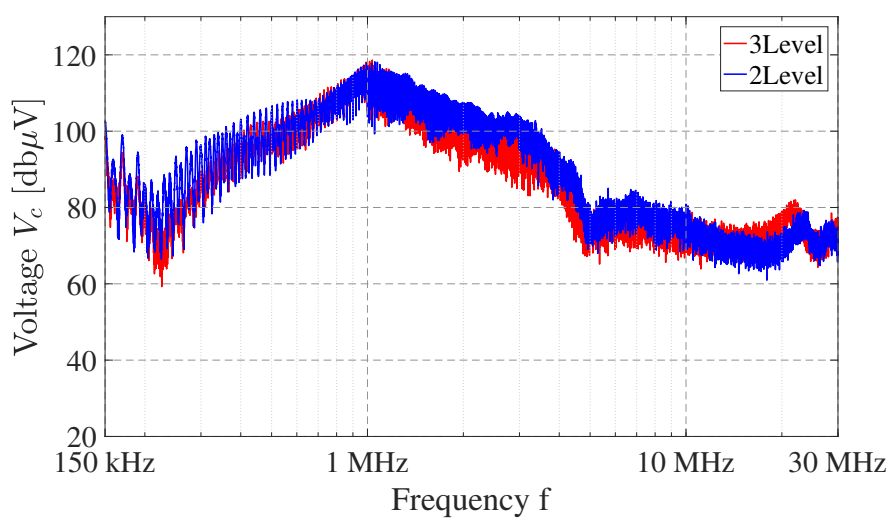

(c)

Fig. 10: Three and two-level noise spectra at positive (a), neutral (b) and negative (c) DC link rail.

One dominant resonance peak occurs around $1 \mathrm{MHz}$, while a second resonance peak is located around $25 \mathrm{MHz}$. According to [6], the dominant resonance peak is referred to as load resonance. It is caused by the parasitic parallel capacitance of 
the RL load, forming a high impedance at resonance frequency. According to [6], the peak value of the load-resonance is marginally influenced by the inverter type, as for example a three-level Si NPC or a two-level SiC inverter. It is rather affected by the DC-link voltage. Therefore, the two-level and the three-level operation show just a slight difference around this frequency range. A similar peak value can be observed for each of the outputs and for both modulation techniques, whereas the side-bands of the peak show an increased noise of up to $6 \mathrm{~dB}$ when using two-level operation in comparison to three-level-operation. The second resonance peak is referred to as module resonance, forming a high impedance in the semiconductor power-module. It depends on the used power module and the switching characteristic [6]. As can be seen from the three LISN outputs, the module resonance is not symmetrical. The highest noise is observed on the neutral point conductor $\left(V_{b}\right)$. Around this region, the noise is reduced by 3 to $6 \mathrm{~dB}$, when using two-level operation in comparison to theelevel-operation.

Fig. 11(a) and 11(b) show the CM and line-DM $\left(V_{\mathrm{DM}, a b}\right)$ spectrum, respectively. Since the three line-DM spectra show similar noise levels, just $V_{\mathrm{DM}, a b}$ is shown here. As expected

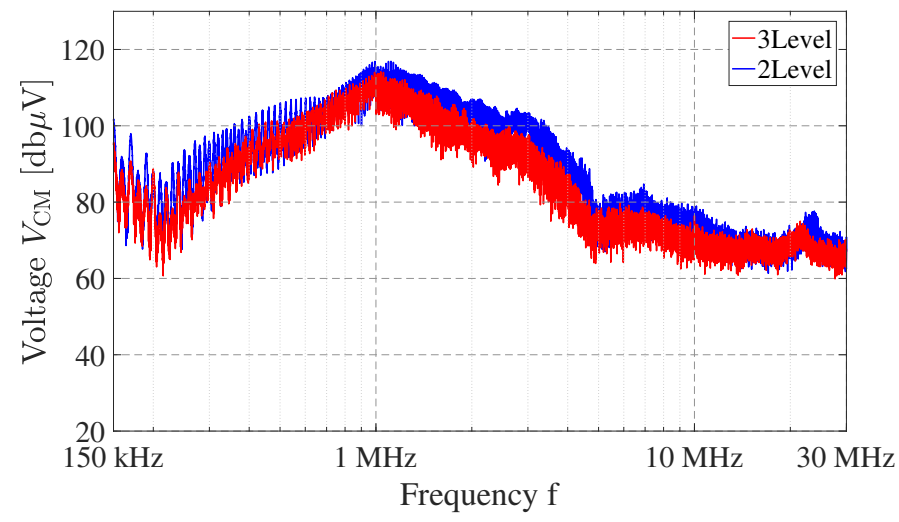

(a)

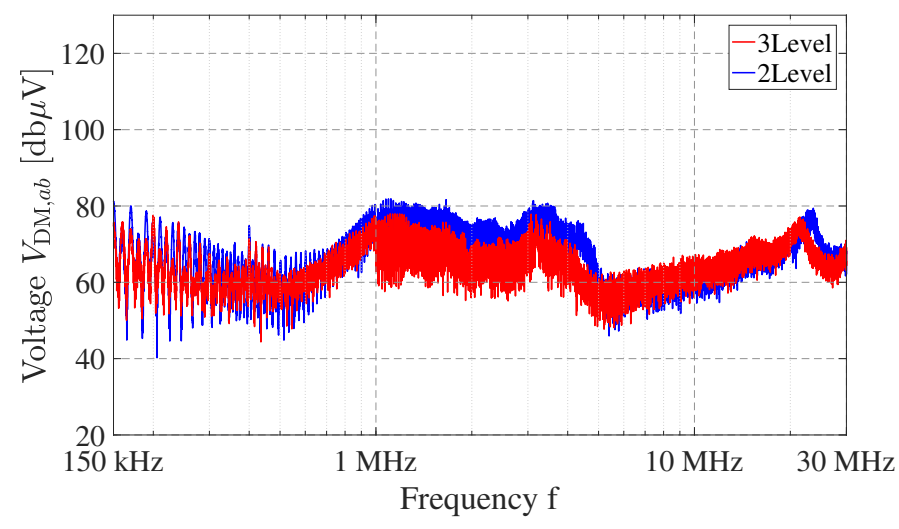

(b)

Fig. 11: Measured common mode (a) and differential mode (b) noise.

from [3], the CM is also predominant for the three-level NPC inverter with connected neutral point. It can be seen that the noise levels, using two-level operation, are slightly increased by 3 up to $6 \mathrm{~dB}$ for both, CM and DM. Furthermore, it is observed that the load resonance is driven by the CM, whereas the module resonance is driven by the DM [6].

\section{CONCLUSION}

Due to the additional neutral-point connection, the threelevel NPC inverter's DC side forms a three-wire CM/DM system. This paper has shown an approach to separate the three-wire noise for a three-level NPC inverter with a connected neutral point, using a hardware separator based on HF transformers. A very compact prototype of the separator has been built and its CM/DM frequency characteristic has been measured, showing reasonable noise transmission and rejection ratios. An EMI test-bed with three LISNs has been used to measure the conducted noise of the NPC inverter. The noise has been separated into CM and DM quantities. For the investigation, the inverter has been operated with two-level and three-level modulation. It has been seen that the CM noise is predominant, while two typical resonance peaks have been observed. The dominant resonance peak is related to the loadresonance, while the second peak has been caused by the used power modules. It has been seen that the machine-resonance was driven by the $\mathrm{CM}$, whereas the module-resonance was driven by the DM. Furthermore, it has been seen that the three-level in comparison to the two-level operation is reducing the noise levels by 3 to $6 \mathrm{~dB}$.

\section{REFERENCES}

[1] International Special Committee on Radio Interference (CISPR), "Vehicles, boats and internal combustion engines - radio disturbance characteristics - limits and methods of measurement for the protection of on-board receivers," CISPR 25:2016, IEC, Standard,, 2016.

[2] X. Gong and J. A. Ferreira, "Comparison and reduction of conducted emi in sic jfet and si igbt-based motor drives," IEEE Transactions on Power Electronics, vol. 29, no. 4, pp. 1757-1767, April 2014.

[3] K. Oberdieck, J. Gossmann, A. Bubert, and R. W. De Doncker, "Common- and differential-mode separators including the fmbroadcasting band," in PCIM Europe 2018; International Exhibition and Conference for Power Electronics, Intelligent Motion, Renewable Energy and Energy Management, June 2018, pp. 1-8.

[4] K. Oberdieck, A. Sewergin, and R. W. De Doncker, "Influence of the voltage-dependent output capacitance of sic semiconductors on the electromagnetic interference in dc-dc converters for electric vehicles," in 2017 International Symposium on Electromagnetic Compatibility EMC EUROPE, Sep. 2017, pp. 1-6.

[5] K. Oberdieck, A. Wienhausen, A. Sewergin, A. Stippich, J. Henn, and R. W. De Doncker, "Electromagnetic Emissions by Three Different Concepts of Bidirectional Multi-Phase SiC DC-DC Boost Converters," in Conference for Power Electronics, Intelligent Motion, Renewable Energy and Energy Management (PCIM Europe), 2019.

[6] A. Bubert, K. Oberdieck, H. Xu, and R. W. De Doncker, "Experimental validation of design concepts for future ev-traction inverters," in 2018 IEEE Transportation Electrification Conference and Expo (ITEC), June 2018, pp. 795-802.

[7] L. M. Tolbert, F. Z. Peng, and T. G. Habetler, "Multilevel inverters for electric vehicle applications," in Power Electronics in Transportation (Cat. No.98TH8349), Oct 1998, pp. 79-84.

[8] A. Kersten, K. Oberdieck, A. Bubert, M. Neubert, E. Grunditz, T. Thiringer, and R. W. De Doncker, "Fault detection and localization for limp home functionality of three-level npc inverters with connected neutral point for electric vehicles," IEEE Transactions on Transportation Electrification, pp. 1-1, 2019.

[9] A. Kersten, E. Grunditz, and T. Thiringer, "Efficiency of active threelevel and five-level npc inverters compared to a two-level inverter in a vehicle," in 2018 20th European Conference on Power Electronics and Applications (EPE'18 ECCE Europe), Sep. 2018, pp. P.1-P.9. 
[10] H. Xu, A. Bubert, M. Laumen, and R. W. De Doncker, "Active neutralpoint balancing of three-level neutral-point-clamped traction inverters," in 2018 21st International Conference on Electrical Machines and Systems (ICEMS), Oct 2018, pp. 2256-2261.

[11] G. I. Orfanoudakis, M. A. Yuratich, and S. M. Sharkh, "Analysis of dclink capacitor current in three-level neutral point clamped and cascaded h-bridge inverters," IET Power Electronics, vol. 6, no. 7, pp. 1376-1389, August 2013.

[12] M. Laumen, M. Schubert, A. Bubert, A. Lamprecht, and R. W. De Doncker, "Optimized space vector modulation for dc-link balancing in three-level neutral-point-clamped inverters for electric drives," in 2017 IEEE 12th International Conference on Power Electronics and Drive Systems (PEDS), Dec 2017, pp. 1,135-1,140.

[13] M. L. Heldwein, "Emc filtering of three-phase pwm converters," Ph.D. dissertation, ETH Zurich, 2008.

[14] M. L. Heldwein, J. Biela, H. Ertl, T. Nussbaumer, and J. W. Kolar,
"Novel three-phase $\mathrm{cm} / \mathrm{dm}$ conducted emission separator," IEEE Transactions on Industrial Electronics, vol. 56, no. 9, pp. 3693-3703, Sep. 2009.

[15] A. Nagel and R. W. De Doncker, "Separating common mode and differential mode noise in emi measurement," EPE Journal, vol. 10, no. 2, pp. 27-30, 2000.

[16] Mini-Circuits, “Tc1-42x+.pdf," https://ww2.minicircuits.com/pdfs/ TC1-42X+.pdf, Datasheet HF-Transformer, (Accessed on 03/26/2019).

[17] Semikron GmbH, http://www.farnell.com/datasheets/1899262.pdf, Datasheet IGBT Module, (Accessed on 04/04/2019).

[18] K. Sharifabadi, L. Harnefors, H.-P. Nee, S. Norrga, and R. Teodorescu, Design, control, and application of modular multilevel converters for HVDC transmission systems. John Wiley \& Sons, 2016.

[19] Plexim GmbH, "Plecs - user manual," https://www.plexim.com/sites/ default/files/plecsmanual.pdf, User Manual, (Accessed on 04/04/2019). 